\title{
2nd Grade Completion
}

National Cancer Institute

\section{Source}

National Cancer Institute. 2nd Grade Completion. NCI Thesaurus. Code C67124.

Indicates that 2 nd grade is the highest level of educational achievement. 